\title{
A new validated endurance performance test.
}

Citation for published version (APA):

Jeukendrup, A. E., Saris, W. H. M., Brouns, F. J. P. H., \& Kester, A. D. M. (1996). A new validated endurance performance test. Medicine and Science in Sports and Exercise, 28(2), 266-270. https://doi.org/10.1097/00005768-199602000-00017

Document status and date:

Published: 01/01/1996

DOI:

10.1097/00005768-199602000-00017

Document Version:

Publisher's PDF, also known as Version of record

\section{Please check the document version of this publication:}

- A submitted manuscript is the version of the article upon submission and before peer-review. There can be important differences between the submitted version and the official published version of record.

People interested in the research are advised to contact the author for the final version of the publication, or visit the DOI to the publisher's website.

- The final author version and the galley proof are versions of the publication after peer review.

- The final published version features the final layout of the paper including the volume, issue and page numbers.

Link to publication

\footnotetext{
General rights rights.

- You may freely distribute the URL identifying the publication in the public portal. please follow below link for the End User Agreement:

www.umlib.nl/taverne-license

Take down policy

If you believe that this document breaches copyright please contact us at:

repository@maastrichtuniversity.nl

providing details and we will investigate your claim.
}

Copyright and moral rights for the publications made accessible in the public portal are retained by the authors and/or other copyright owners and it is a condition of accessing publications that users recognise and abide by the legal requirements associated with these

- Users may download and print one copy of any publication from the public portal for the purpose of private study or research.

- You may not further distribute the material or use it for any profit-making activity or commercial gain

If the publication is distributed under the terms of Article $25 \mathrm{fa}$ of the Dutch Copyright Act, indicated by the "Taverne" license above, 


\section{MEDICINE \& SCIENCE IN SPORTS \& EXERCISE}

LIPPINCOTT WILLIAMS \& WILKINS

(C) Williams \& Wilkins 1996. All Rights Reserved.

Volume 28(2) February $1996 \quad$ pp 266-270

A new validated endurance performance test

[Special Communications: Methods]

JEUKENDRUP, ASKER; SARIS, WIM H. M.; BROUNS, FRED; KESTER, ARNOLD D. M.

Nutrition Research Centre Department of Human Biology, Department of Medical Methodology and Statistics, University of Limburg, Maastricht, THE NETHERLANDS

Submitted for publication November 1994.

Accepted for publication April 1995.

The authors would like to express appreciation to Patrick Schrauwen, Richard van Diesen, Marco Mensink, Lars Borghouts, Kim Peeters, and Jean Herpers for the time-consuming help in data collection. We also want to thank Loek Wouters for the excellent technical assistance.

This study was supported by an Isostar Research Grant by Sandoz Nutrition Ltd., Berne, Switzerland.

Address for correspondence: Asker E. Jeukendrup, Department of Human Biology, University of Limburg, P.O. Box 616, 6200 MD Maastricht, The Netherlands.

\section{Browse Table \\ of Contents}

Outline

- ABSTRACT

- METHODS

O $\underline{\text { Subjects }}$

O $\underline{\text { Pretest }}$

Protocol

Statistics

- RESULTS

O Protocol A

O Protocol B

O Protocol C

- DISCUSSION

- $\underline{\text { REFERENCES }}$

Graphics

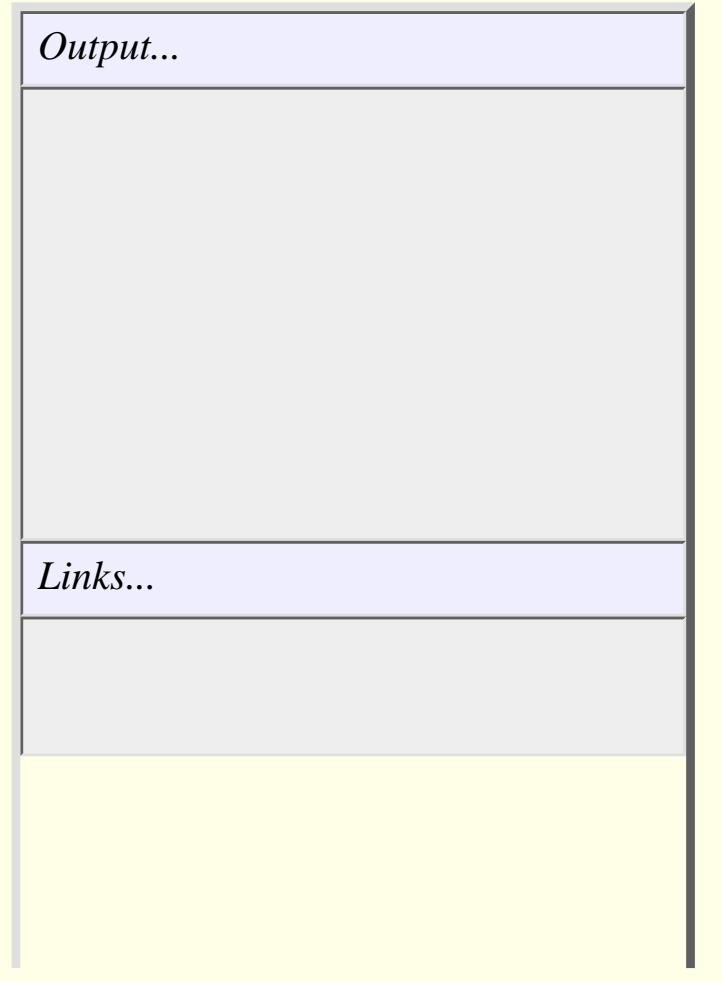


- Equation $1 \mathrm{H}$

- Table 1

- Equation 1I

- Table 2

- Equation 1J

Table 3

- Table 4

History...

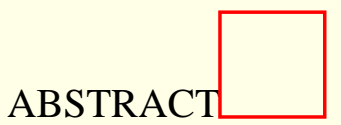

A new validated endurance...

The extensive use of performance tests in diet intervention studies mirrors the importance of such a measurement. Although many different endurance performance tests have been used in the past, the majority of these different protocols has never been validated. In this study reproducibility of three different endurance performance tests was evaluated. Thirty well-trained subjects were matched on age, weight, and Wmax and divided into three subgroups. Each group of subjects performed one of three exercise protocols: protocol (A) consisted of cycling at 75\% Wmax until exhaustion. In (B) subjects received a preload of $45 \mathrm{~min} 70 \% \mathrm{Wmax}$ and then performed as much work as possible in $15 \mathrm{~min}$. (C) consisted of a time trial, in which subjects had to complete a preset amount of work as fast as possible. Each subject performed one of the trials six times. Coefficient of variation $(\mathrm{CV})$ was calculated for each protocol. $\mathrm{CV}(\mathrm{A})$ was $26.6 \%, \mathrm{CV}(\mathrm{B}) 3.49 \%$, and $\mathrm{CV}(\mathrm{C}) 3.35 \%$. It was concluded that reproducibility of a test at $75 \% \mathrm{Wmax}$ until exhaustion is poor and these tests are not reliable. Time trial protocols may result in better performance evaluation.

In exercise physiology, methods to evaluate aerobic and anaerobic power of athletes have been studied extensively, but so far only scarce literature is available on the reproducibility of endurance performance tests. On the other hand, there appears to be an increasing demand to evaluate the effects of nutrition, ergogenic aids, drugs, or training programs on endurance performance. A quick review through some recent literature shows that no uniform "endurance performance test" exists, but a wide variety of different exercise protocols is used. Testing methodologies have traditionally included submaximal performance rides at a fixed percentage of maximal oxygen uptake $\left(\cdot \mathrm{VO}_{2 \max }\right)$ or maximal power output $(\mathrm{Wmax})$.

Coyle et al. (2) report that time to exhaustion during prolonged exercise at a constant work output was highly correlated with 40-km time trial performance. However, Krebs and Powers (5) report poor test-retest reliability of time to fatigue. Because of the lack of a standard and well validated performance test, it is often concluded that "there is no effect," whereas with the performance test applied it was not possible to detect "the effect." Therefore, the aim of this study was to investigate the reproducibility of three different endurance performance tests under carefully controlled conditions.

METHODS

Subjects

To investigate the reproducibility of different endurance performance tests, 30 well-trained competitive or recreational male triathletes or cyclists were recruited. These subjects were all actively cycling for at least $3 \mathrm{yr}$ and involved in endurance training on a regular basis ( $>4$ times $\cdot \mathrm{wk}^{-1}$ ). The study was approved by the local medical ethical committee and subjects signed an informed consent. Subjects characteristics are listed in $\underline{\text { Table } 1 .}$.

Graphic

[Help with image viewing]

[Email Jumpstart To Image]
TABLE 1. Characteristics of the 30 subjects and the three matched groups. 
Pretest

In a pretest, maximal workload (Wmax) was determined using a graded exercise test according to Kuipers et al. $\underline{(6)}$. After a warm-up period of $5 \mathrm{~min}$ at $100 \mathrm{~W}$, workload was increased by $50 \mathrm{~W}$ every $2.5 \mathrm{~min}$ until a heart rate was reached of $160 \mathrm{bpm}$. Then workload was increased by $25 \mathrm{~W}$ every $2.5 \mathrm{~min}$. The Wmax was determined by the following formula:Equation where Wout is the workload of the last completed stage and $t$ is the time in seconds in the final stage.

Graphic

[Help with image viewing]

Equation $1 \mathrm{H}$

[Email Jumpstart To Image]

Heart rate was continuously measured by a Sport-tester ${ }^{\circledR}$ (Polar, Finland). Like $\cdot \mathrm{VO}_{2 \max }$, Wmax is a good predictor of aerobic capacity $(1,3,7)$. The ergometers used (Lode Excalibur Sport, Lode, Groningen, The Netherlands) are electromagnetically braked, but are able to switch from a pedaling rate independent mode(hyperbolic mode) to a pedaling rate dependent mode (linear mode). In the hyperbolic mode a certain work rate can be imposed to a subject and this load will be constant, independent of the subjects' pedaling rates. In the linear mode the ergometer acts like a mechanically braked ergometer: with increasing pedaling rate, the work rate will increase according to the following formula:Equation

Graphic

[Help with image viewing]

[Email Jumpstart To Image]

in which RPM is the pedaling rate and L is a (constant) linear factor. The ergometers are calibrated yearly and deviation is $<0.5 \%$ even at very high work rates.

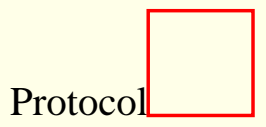

Thirty subjects were randomly divided into three groups of 10 subjects, matched for age, weight, and Wmax. Each subgroup was assigned to one of three test protocols: A, B, or C (Table 1).

Each subject performed the protocol to which he was assigned, six times, including a learning trial. This learning trial was not included in the statistical analysis. To avoid any influence of circadian variance, subjects performed their tests at the same time of the day. Subjects were not allowed to train the day before the test. Two days before the test, training was not allowed to be exhaustive.

Additionally, all subjects were instructed to eat the same meal the evening before the test, preferably a high carbohydrate meal such as pasta. In the hour preceding the test, subjects were not allowed to eat. To further control carbohydrate and energy intake, food records were provided for the day before the test and the day of the test. During all tests environmental conditions were standardized, temperature was kept at $20^{\circ} \mathrm{C}$, and relative humidity varied between $50 \%$ and $60 \%$.

Subjects were encouraged by the same person every test and water was available ad libitum. Tests were designed in such a way that they all lasted about $1 \mathrm{~h}$ in an attempt to keep total energy expenditure comparable.

Protocol A: continuous exercise at 75\% Wmax. After a short warm-up (5 min, $100 \mathrm{~W}$ ), subjects exercised at $75 \%$ of their maximal power output until exhaustion on an electromagnetically braked ergometer. After the first test, workload was adjusted if necessary to ensure that all subjects would perform for approximately $1 \mathrm{~h}$. By doing this the intersubject variability was minimized and the (subjective) experienced intensity of exercise became the same for all subjects. During the test, subjects were unaware of time or any other variable (like heart rate) and the only information subjects received was the pedaling rate. The test was aborted when pedaling rate dropped below $60 \mathrm{rpm}$. The time from the start of the experiment till the point of exhaustion, expressed in minutes was the measure of performance. 
Ovid: JEUKENDRUP: Med Sci Sports Exerc, Volume 28(2).February 1996.266-270

Protocol B: preloaded time trial. These test was started with a preload of $45 \mathrm{~min}$ at $70 \% \mathrm{Wmax}$. Thereafter a 15 -min time trial followed in which subjects had to perform as much work as possible. During the first 45 min the electromagnetically braked ergometers were in the hyperbolic mode, so that the work rate $(70 \% \mathrm{Wmax})$ was independent of pedaling rate. During the 15-min time trial the ergometer was in the linear mode so that with increasing pedaling rate the work rate increased. In this way the subject could pace himself and try to maintain a high pedaling rate over $15 \mathrm{~min}$ to maximize power output.

The subjects were motivated to perform as much work as possible in $15 \mathrm{~min}$. The total amount of work (power output over 15 $\mathrm{min}$ ) was taken as a measure of performance. To avoid test retest influence, the subject received no information about the amount of work performed, heart rate, or pedaling rate. The subjects were only aware of time. The cycle ergometer was connected to a computer which recorded the work rate every second and immediately calculated the total amount of work performed.

Protocol C: 1-h time trial. A time trial was simulated in which the ergometer was set in the pedaling rate dependent (linear) mode. After a short warm-up ( $5 \mathrm{~min}, 100 \mathrm{~W}$ ) subjects were asked to perform a certain amount of work (equal to about $1 \mathrm{~h}$ cycling) as fast as possible. The measure of performance was the time to complete the target amount of work.

This target amount of work was based on the maximal workload (Wmax). Because the aim of the test was to provoke the same energy expenditure as a test at $75 \%$ Wmax until exhaustion which will last about $1 \mathrm{~h} \mathrm{(3600} \mathrm{s),} \mathrm{the} \mathrm{target} \mathrm{amount} \mathrm{of} \mathrm{work}$ was calculated according to the formula: Equation

\section{Graphic}

[Help with image viewing]

Equation 1J

[Email Jumpstart To Image]

The ergometer was set in the linear mode according to the formula: $\mathrm{W}=\mathrm{L} \cdot(\mathrm{RPM})^{2} \cdot$ was $\mathrm{L}$ was chosen in a way which would cause a pedaling rate of $90 \mathrm{RPM}$ at $70 \% \mathrm{Wmax}$. In other words, the linear factor was dependent on the subjects Wmax. This would mean that 75\% Wmax could be achieved at about 100 RPM, which appeared to be the preferential pedaling rate of most cyclists.

The same adaptations to the workload adjuster had to be made as in protocol B: workload and time were registered from which the amount of work could be calculated. During this test the subject was informed about the percentage of the total preset work that had already been performed. He did not receive information on workload, pedaling rate, time, and heart rate.

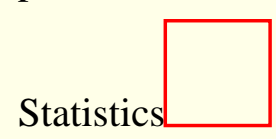

The presence of an order effect was tested within each protocol with a repeated measures analysis of variance (ANOVA). Individual coefficients of variation $(\mathrm{CV})$ were calculated for each subject and averaged within protocols to obtain an overall $\mathrm{CV}$. Equality of the CV between protocols was tested with the Mann-Whitney test.

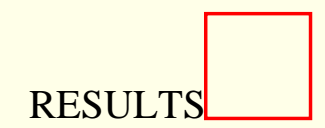

No differences existed between the three groups with respect to age, height, weight, Wmax and Wmax per kg body weight (Table 1). Results are shown in Tables 2-4.

Graphic

[Help with image viewing]

[Email Jumpstart To Image]
TABLE 2. Results of protocol A: 75\% Wmax until exhaustion.

TABLE 3. Results of protocol B: 45 min $65 \%$ Wmax followed by 15 -min time trial. 
Protocol A

During the learning trial of protocol A subjects exercised at $291 \pm 24 \mathrm{~W}$. After this test the workload was slightly adjusted, so that during the five experimental trials the test would last approximately $1 \mathrm{~h}$. The work rate of six subjects was reduced (10-20 W) whereas three subjects remained at the original workload. The original work rate was $291 \pm 22 \mathrm{~W}$ and the work rate after the adjustments was $282 \pm 23 \mathrm{~W}$. One subject dropped out. Times until exhaustion during the five experimental trials in chronological order were: 60, 41, 64, 71, and $68 \mathrm{~min}$. (For accuracy, the results are expressed in seconds in Table 2.) This resulted in a coefficient of variation (CV) of $26.6 \%$. Individual CV ranged from $17.4 \%$ to $39.5 \%$. No test order effects were observed.
Protocol B

Linear factors varied within the range of 0.035-0.044 depending on the subjects Wmax. The amount of work performed during the 15-min time trial ranged from $272 \pm 24.2 \mathrm{~W}$ to $282.2 \pm 31.1 \mathrm{~W}$ during the five experimental trials (Table 3). Individual CV ranged from $1.7 \%$ to $5.8 \%$. This resulted in a mean CV of 3.5\%. No significant differences between the tests were observed so there appeared to be no test order effects. Even when the learning trial was included in the analysis, there was no test order effect.

Protocol $\mathrm{C}$

The time to complete the preset amount of work varied between $3618 \pm 195 \mathrm{~s}$ ([approximately equal to] $60 \pm 3 \mathrm{~min} ; \underline{5}$ ) and $3826 \pm 232 \mathrm{~s}$ ([approximately equal to $] 64 \pm 4 \mathrm{~min} ; 1$ ) (see Table 4). As in protocols A and B, no significant differences between the tests were observed so there appeared to be no test order effects. Even when the learning trial was included in the analysis, there was no test order effect. Individual CV ranged from $0.8 \%$ to $5.8 \%$. Mean $\mathrm{CV}$ for this test was $3.4 \%$.

Both protocols B and C show significantly lower CV than protocol A (bothP-values $<0.0001$ ). The $\mathrm{CV}$ for protocols B and C were not significantly different $(\mathrm{P}=0.88)$.

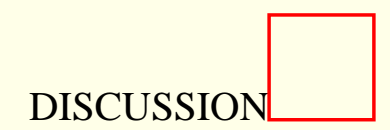

A continuous protocol at a submaximal load until exhaustion is the classical and most common performance test. In the past most endurance performance tests have been performed at exercise intensities ranging from $60 \%$ to $90 \% \cdot \mathrm{VO}_{2 \max }$ until exhaustion. The most remarkable finding of the present study is the poor reproducibility of a continuous exercise protocol until exhaustion (CV 26.6\%). This is in close agreement with Krebs and Powers (5), who were the first to mention that reports concerning the reliability of performance tests were noticeably absent from the literature. Hence, they examined the reliability of cycling in a laboratory at approximately $80 \% \cdot \mathrm{VO}_{2 \max }$. They maintained the $\cdot \mathrm{VO}_{2}$ at a constant level by adjusting the workload. Subjects were tested twice, $4 \mathrm{~h}$ postprandial at the same time of the day, and they were verbally encouraged to exercise as long as possible. The interclass correlation coefficient for the two trials was $r=0.51\left(r^{2}=0.26\right)$. Furthermore, within-subject test-retest variability ranged from $5.2 \%$ to $55.9 \%($ mean $=20.3 \%)$.

We therefore agree with Krebs and Powers (5) that this kind of performance test is not reliable. The observed poor 
reproducibility might be explained by the fact that psychological factors may contribute to significant changes of performance independent of the experimental manipulation. Because these tests have an "open end," psychological factors that might influence performance, such as motivation, monotony, and boredom, are more pronounced than in the time trial oriented approach where the "endpoint is known."

Endurance performance tests with a known endpoint (a certain target amount of work or time), such as the time trial protocols in the present study, appear to be highly reproducible. Time trial protocols B and C had CV of 3.5\% and 3.4\%, respectively. In a study by Coyle et al. (2), performance of elite national-class cyclists was evaluated by determining the highest average work rate that each subject could maintain for $1 \mathrm{~h}$ using a Monark ergometer. The subjects were allowed to vary both the resistance on the flywheel and pedal cadence, which were monitored continuously, in selecting the power output. The subjects cycled intermittently for 1- to 2-min periods at the approximate performance work rate as a part of their warm-up. The initial work rate was set upon a performance prediction from the results of the previous day's lactate evaluation as well as from the subjects' perception during the warm-up. The subjects were instructed to maintain this initial work rate for 8 min, after which it could be adjusted up and down. During the test the subjects had a visual display of the elapsed time, pedal cadence, flywheel resistance, work rate, and heart rate. They were strongly encouraged by the investigators. It was concluded that their actual road racing 40-km time trial performance was highly correlated with average absolute power during the 1-h laboratory performance test $(\mathrm{r}=-0.88 ; \mathrm{P}<0.001)$.

Hickey et al. (4) validated a time trial cycling performance test consisting of a test on a computerized cycle ergometer in an isokinetic mode. Subjects were instructed to complete a fixed work output as fast as possible and were allowed to adjust cadence in $5 \mathrm{rpm}$ increments. Eight subjects completed 12 trials involving four successive performance rides at three total work outputs $(1600,200$, and $14 \mathrm{~kJ})$, comparable to 40, 5, and 0.5 miles. A shorter time to complete the task indicated improved performance. Performance time in the LT was approximately $105 \mathrm{~min}$, in the MT $12 \mathrm{~min}$, and the ST $0.5 \mathrm{~min}$. The mean coefficient of variation (CV) for the medium (MT, $200 \mathrm{~kJ}$ ) and long trial $(\mathrm{LT}, 1600 \mathrm{~kJ})$ rides were $0.95 \%$ and $1.01 \%$, respectively. The $\mathrm{CV}$ for the short trial $(\mathrm{ST}, 14 \mathrm{~kJ})$ ride was significantly greater than the $\mathrm{CV}$ for MT and LT, respectively. However, trial 4 in the LT was significantly faster than the other trials. The authors attributed this to the knowledge of the subjects that this was their last test. It was suggested that trained cyclists are able to reproduce endurance performance in a time trial protocol as described with a coefficient of variation of approximately $1.0 \%$. This is also in agreement with the present findings, where a CV of 3.5\% was found for a preloaded time trial (protocol B) and a CV of 3.4\% for protocol C. Furthermore, protocols B and $\mathrm{C}$ are more practice oriented whereas protocol A is a rather unusual type of performance. The fact that the $\mathrm{CV}$ was much smaller in this type of trial might be related to the fact that subjects know when they will finish in contrast to trial A which is open-ended.

There appeared to be no learning effect or any other test order effect during the three different trials. This implies that it is not necessary to perform an extra learning trial before the start of a study with one of the performance tests described. However, the subjects in the present study were already customized to the procedures at the lab and had performed exercise tests before.

In conclusion, the classical exercise protocol for measuring endurance performance (exercise time until exhaustion) in cyclists is not reliable unless the workload is related to the lactate threshold (2). Time trial protocols, such as described above, appear

to be much more reliable since their reproducibility is higher. In these tests there appears to be no learning effect or time trend in well-trained cyclists or triathletes.

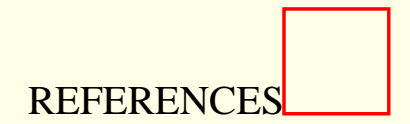

1. Arts, F. J. P., H. Kuipers, A. E. Jeukendrup, and W. H. M. Saris. A short cycle ergometer test to predict maximal workload and maximal oxygen uptake. Int. J. Sports Med. 14:460-464, 1993. Bibliographic Links [Context Link]

2. Coyle, E. F., M. E. Feltner, S. A. Kautz, et al. Physiological and biomechanical factors associated with elite endurance cycling performance. Med. Sci. Sports Exerc. 23:93-107, 1991. Bibliographic Links [Context Link]

3. Hawley, J. A. and T. D. Noakes. Peak power output predicts maximal oxygen uptake and performance time in trained cyclists.Eur. J. Appl. Physiol. 65:1992. [Context Link]

4. Hickey, M. S., D. L. Costill, G. K. McConell, J. J. Widrick and H. Tanaka. Day to day variation in time trial cyling performance.Int. J. Sports Med. 13:467-470, 1992. Bibliographic Links [Context Link] 
Ovid: JEUKENDRUP: Med Sci Sports Exerc, Volume 28(2).February 1996.266-270

5. Krebs, P. S. and S. K. Powers. Reliability of laboratory endurance tests. Med. Sci. Sports Exerc. 31: 1989. [Context Link]

6. Kuipers, H., F. T. J. Verstappen, H. A. Keizer, P. Geurten and G. van Kranenburg. Variability of aerobic performance in the laboratory and its physiologic correlates. Int. J. Sports Med. 6:197-201, 1985. [Context Link]

7. Storer, T. W., J. A. Davis and V. J. Caiozzo. Accurate prediction of $\cdot \mathrm{VO}_{2 \max }$ in cycle ergometry. Med. Sci. Sports Exerc. 22:704-712, 1990. Bibliographic Links [Context Link]

EXERCISE TESTING; WORK RATE; TIME TRIAL; CYCLING

Accession Number: 00005768-199602000-00017

Browse Table

of Contents

Copyright (c) 2000-2004 Ovid Technologies, Inc.

Version: rel9.2.0, SourceID 1.9998.1.313 